\title{
Endothelin-1 increase in aqueous humour caused by frequency- doubled Nd:YAG laser trabeculoplasty in rabbits
}

\begin{abstract}
Purpose To study the effect of Nd:YAG laser trabeculoplasty (LT) on endothelin-1 (ET-1) concentration of aqueous humour and intraocular pressure (IOP) in rabbits. Methods One eye of each of 18 pigmented rabbits was subjected to $360^{\circ} \mathrm{LT}$ with a frequency-doubled Nd:YAG laser (532 nm), and IOP was measured with a Tono-Pen tonometer before treatment. Post-LT IOP measurements followed by aqueous humour aspiration were performed under general anaesthesia at 3 and $12 h$ and 1, 3 and 7 days after the treatment. The concentration of ET-1 in aqueous humour was measured by means of a radioimmunoassay.

Results In the eyes that had undergone LT, the concentrations of ET-1 in the aqueous humour were significantly increased at 3,12 and $24 \mathrm{~h}$ after the treatment compared with the contralateral eyes. ET- 1 concentrations at 3 and 7 days after LT, however, did not differ significantly from the corresponding contralateral control values. IOP increased following the treatment at 3 and $12 \mathrm{~h}$. IOP values were significantly lower in the treated eyes at 1, 3 and 7 days after the treatment than in the control eyes.

Conclusions The results show that LT in rabbits was followed by an immediate and short-term increase in aqueous humour ET-1 that might be caused by leakage from uveal tissue. This may be responsible for the release of prostaglandins causing the IOP increase and inflammatory complications of LT.
\end{abstract}

Key words Endothelin-1, Frequency-doubled Nd:YAG laser, Intraocular pressure, Laser trabeculoplasty, Rabbit

The contractility of blood vessels is regulated by various neural and hormonal signals together with the local regulatory mechanisms intrinsic to the blood vessel wall. The endothelins (ETs), a recently discovered family of peptides, are among the most potent known vasoconstrictor peptides and seem to have an important role in the regulation of ocular perfusion. Endothelin-1 (ET-1) was first purified from the conditioned media of vascular endothelial cells. ${ }^{1,2}$ The levels of messenger RNA for ET in the iris are among the highest of any tissue. A high density of binding sites for ET has been found in the corneal endothelium, iris, ciliary body and ciliary processes. Exogenous ET-1 injected into the anterior chamber has been observed to cause a biphasic intraocular pressure (IOP) change in the rabbit: a pressure rise is seen within the first $2 \mathrm{~h}$ after administration, followed by a prolonged IOP decrease. ${ }^{3}$

When the laser is used to photocoagulate uveal tissue, the rabbit eye undergoes a pattern of changes consisting of miosis, conjunctival and iris hyperaemia, increased IOP and breakdown of the blood-aqueous barrier. The pattern of ocular changes and the severity of the response depend on the type of laser injury. Prostaglandins and neural elements are both involved in the mediation of this response. ${ }^{4-7}$

The frequency-doubled $(532 \mathrm{~nm})$ green $\mathrm{Nd}$ :YAG laser was first suggested as a possible replacement for the argon laser in 1971 by L'Esperance. ${ }^{8}$ The gross morphology and light microscopic histopathology showed that the $\mathrm{Nd}$ :YAG and argon wavelengths produced similar lesions when a high repetition pulse rate and low peak powers are used. ${ }^{8}$

Laser trabeculoplasty (LT) causes a temporary disruption of the blood-ocular barrier resulting in aqueous protein flare, and there is evidence that this is mediated by prostaglandins, which can be synthesised by the trabecular meshwork. Post-LT flare is maximal at $48 \mathrm{~h}$ and there is a positive correlation at this time between the level of inflammation and IOP change. ET causes the release of eicosanoids, prostaglandin $\mathrm{I}_{2}\left(\mathrm{PGI}_{2}\right)$, prostaglandin $\mathrm{E}_{2}\left(\mathrm{PGE}_{2}\right)$ and thromboxane $\mathrm{A}_{2}\left(\mathrm{TXA}_{2}\right)$. In the rabbit eye, concentrations of prostanoids following photocoagulation were related to the number of
M. Guzey

A. Satici

Department of Ophthalmology Harran University, School of Medicine Sanliurfa, Turkey

\section{H. Vural}

Department of Clinical

Biochemistry

Harran University,

School of Medicine

Sanliurfa, Turkey

Mustafa Guzey, MD Forsa Sok. Guney Ap. No 21 Daire 1

Senesenevler Bostanc Istanbul, Turkey

Tel/fax: +90 4143137837

e-mail: guzey@turk.net

Received: 17 July 2000 Accepted in revised form: 6 April 2001 
Table 1. Concentration of ET-1 in aqueous humour samples following laser trabeculoplasty and in the control group

\begin{tabular}{lccccc}
\hline & \multicolumn{5}{c}{ ET-1 concentration $(\mathrm{pg} / \mathrm{ml})$} \\
\cline { 2 - 6 } Group & Hour 3 & Hour 12 & Day 1 & Day 3 & Day 7 \\
\hline Untreated & $11.6 \pm 4.4$ & $10.2 \pm 5.1$ & $11.8 \pm 3.9$ & $10.7 \pm 4.2$ & $9.9 \pm 4.5$ \\
Treated & $117.8 \pm 36.7^{* * *}$ & $58.3 \pm 21.6^{* *}$ & $41.2 \pm 24.4^{* *}$ & $11.4 \pm 4.9^{*}$ & $10.3 \pm 3.8^{*}$ \\
\hline
\end{tabular}

Values are mean \pm SD.

Paired $t$-test: ${ }^{* * *} p<0.00001 ;{ }^{* *} p<0.0001 ;{ }^{*} p>0.05$.

adminstered laser lesions and prostanoid release was associated with an initial hypertensive response and disruption of the blood-aqueous barrier with plasma leakage. ${ }^{4}$

Little is known about the role of endogenous ETs in different laser treatment modalities used to reduce IOP in glaucoma. To evaluate the potential impact of intraocular ET-1 changes on IOP following Nd:YAG LT, we investigated the connections between $\mathrm{LT}$, aqueous humour ET-1 concentration and IOP.

\section{Materials and methods}

A total of 18 pigmented rabbits without ocular abnormalities and weighing between 3 and $4 \mathrm{~kg}$ were used for the experiments. One eye per animal was treated, and the other eye remained intact. IOP measurements, laser treatments and aspiration of aqueous humour were performed under general anaesthesia with intramuscular injection of ketamine hydrochloride $(25 \mathrm{mg} / \mathrm{kg}$ ) and xylazine hydrochloride (5 $\mathrm{mg} / \mathrm{kg}$ ). The animals were cared for in accordance with the Association for Research in Vision and Ophthalmology Statement for the Use of Animals in Ophthalmic and Vision Research.

IOP was measured with a Tono-Pen tonometer (Mentor O\&O, Santa Barbara, CA) before treatment. Post-LT IOP measurements followed by aqueous humour aspiration were performed at 3 and $12 \mathrm{~h}$ and 1, 3 and 7 days after the treatment. Mean readings based on a series of five measurements with less than $5 \%$ spread were accepted.

One eye of each rabbit was subjected to a $360^{\circ} \mathrm{LT}$ with a $532 \mathrm{~nm}$ frequency-doubled green $\mathrm{Nd}$ :YAG laser (Oculight GL-IRIS Medical Instruments) via a Trokel F/3 Gonio laser lens (Ocular Instruments), spot size $75 \mu \mathrm{m}$ (68 $\mu \mathrm{m}$ in target tissue with Trokel lens), duration $50 \mathrm{~ms}$, power $800 \mathrm{~mW}$, number of laser spots 100 in $360^{\circ}$. Treatment was conducted with adjacent but not overlapping spots. The desired response was blanching of the pigmented trabecular meshwork with or without minimal bubble formation.

The anterior chamber aqueous humour was withdrawn from both the treated and untreated eyes of each rabbit (using a 26 gauge needle and a tuberculin syringe) at 3 and $12 \mathrm{~h}$ and 1, 3 and 7 days after the treatment. The central cornea was cannulated, and then the samples were immediately frozen and stored at $-70{ }^{\circ} \mathrm{C}$ until assay.

For the assay, we used an in-house radioimmunoassay utilising a polyclonal antibody against ET-1 (Peninsula Laboratories, Belmont, CA). ET-1 for the standards was purchased from Sigma-Aldrich (St Louis, MO). Samples and standards were incubated with antibody for $48 \mathrm{~h}$ at $4{ }^{\circ} \mathrm{C}$. After the addition of approximately $100000 \mathrm{cpm}\left[{ }^{125} \mathrm{I}\right] \mathrm{ET}-1$ (Amersham International, Little Chalfont, UK) per tube, samples were incubated for $24 \mathrm{~h}$. The separation of bound and free ET-1 was carried out by using a goat anti-rabbit second antibody. Samples were assayed in duplicate.

The IOP value was calculated for each group at each follow-up time on treated and untreated eyes, respectively. A paired $t$-test was used to compare IOP and ET-1 concentration changes between the corresponding treated and untreated eyes. A $p$ value less than 0.05 was considered to be statistically significant.

\section{Results}

The concentrations of ET-1 in aqueous humour significantly increased in the treated eyes at 3 and $12 \mathrm{~h}$ and 1 day after the treatment compared with the contralateral control eyes. ET- 1 concentrations at 3 and 7 days after LT, however, did not differ significantly from the corresponding contralateral control values (Table 1).

The difference in IOP change between treated and untreated eyes was statistically significant at each of the follow-up times. In the LT group, at 3 and $12 \mathrm{~h}$ after the laser treatment IOP was significantly higher than the

Table 2. IOP changes following laser trabeculoplasty and in the control group

\begin{tabular}{|c|c|c|c|c|c|}
\hline \multirow[b]{2}{*}{ Group } & \multicolumn{5}{|c|}{ IOP (mmHg) } \\
\hline & Hour 3 & Hour 12 & Day 1 & Day 3 & Day 7 \\
\hline Untreated & $15.2 \pm 4.4$ & $15.6 \pm 3.9$ & $15.4 \pm 4.0$ & $15.9 \pm 4.6$ & $15.1 \pm 5.7$ \\
\hline Treated & $18.7 \pm 6.3^{* *}$ & $19.1 \pm 5.8^{* *}$ & $11.2 \pm 5.1^{* *}$ & $11.1 \pm 4.8^{* *}$ & $11.6 \pm 3.6^{* *}$ \\
\hline
\end{tabular}

Values are mean $\pm \mathrm{SD}$.

Pairted $t$-test: ${ }^{* *} p<0.001$. 
corresponding value for the untreated eyes of the same animals. At 1, 3 and 7 days after treatment, however, IOP was significantly lower in the LT group (Table 2).

\section{Discussion}

ET-1 is a potent peptide vasoconstrictor recently characterised from the supernatant fraction of cultured vascular endothelial cells found in various ocular structures, including the retina, choroid, iris, ciliary body, ciliary epithelium and aqueous humour. When injected intravitreally into the rabbit eye, 4 pmol or less of ETs caused a dose-dependent increase in IOP, but at doses higher than $1 \mathrm{nmol}$ it initially increased and subsequently lowered IOP. ${ }^{9,10}$ The difference in pharmacological effect of low and high doses of ETs is interesting. It is currently believed that the ocular hypertension produced by ETs is mediated by prostaglandins, because pre-treatment of rabbits with systemic indomethacin, a cyclooxygenase inhibitor that inhibits the production of prostaglandins, eliminated this effect. $^{11}$

The mechanism of the lowering of IOP by ETs is unclear. However, Lepple-Wienhues et al. ${ }^{12}$ showed that ET-1 caused contraction of the ciliary muscle strips of the bovine eye. Because tension on the ciliary muscle regulates aqueous outflow and accommodation, ET-1induced contraction of the ciliary muscle should induce accommodation and increase aqueous outflow. It has been shown that ET-1 has concentration-dependent direct effects on the ciliary muscle and on the contractile elements of the trabecular tissue. Higher ET-1 concentrations cause constriction, and lower ET-1 levels cause relaxation. These responses seem to have an important role in both the IOP elevation and decrease induced by ETs. Also, higher ET concentrations can cause arterial vasoconstriction leading to reduce aqueous humour production and an IOP decrease. In fact, when perfused into the anterior chamber of the anaesthetised monkey eye, ET-1 significantly increased the outflow facility and affected accommodation as predicted. ${ }^{3}$ Thus effects of ETs on the ciliary muscle may lead to the modification of IOP.

Abdel-Latif and Zhang $^{13}$ demonstrated that ET-1 caused contraction of both iris sphincter and dilator muscles of the rabbit. Similarly, Lepple-Wienhues and colleagues ${ }^{12}$ showed that ET-1 was a potent contracting agent for bovine trabecular meshwork, considering that a similar signal transduction pathway is likely to be present in human ciliary muscles and that contraction by ET-1 was observed in bovine ciliary muscle strips. ${ }^{12}$

ETs were reported to release arachidonic acid and prostaglandins by stimulating phospholipase $\mathrm{A}_{2}$ in cultured smooth muscle and endothelial cells. ${ }^{14}$ AbdelLatif et al. ${ }^{15}$ observed the same phenomenon in rabbit iris sphincter smooth muscle. The finding that $\mathrm{PGE}_{2}$ concentration in the cell medium was increased by ET-1 provides a further probable mechanism for the cyclic adenosine monophosphate (cAMP) effect of ET-1. ETs activated phospholipase $\mathrm{C}$, calcium mobilisation, $\mathrm{PGE}_{2}$ and cAMP production in human ciliary muscle cells. All these actions apparently were mediated by the $\mathrm{ET}_{\mathrm{A}}$ receptor. ${ }^{16} \mathrm{PGE}_{2}$ was the major prostanoid found and its concentration increased rapidly following laser irradiation. Further, the magnitude of this increase was related to the number of laser lesions adminstered.

Besides $\mathrm{PGE}_{2}$, other prostanoids were identified in the aqueous humour samples, including $\mathrm{PGD}_{2}$ and $\mathrm{PGF}_{2 \alpha}{ }^{4}$ The laser-induced aqueous protein enhancement was closely related to the corresponding changes in aqueous $\mathrm{PGE}_{2}$ content. $\mathrm{PGE}_{1}$ and $\mathrm{PGE}_{2}$ cause a breakdown of the blood-aqueous barrier and an increase in IOP. Increased formation of prostaglandins is thus a likely mode of action of the ETs in the rabbit. ${ }^{17}$ Since the effects of ETs on the blood-aqueous barrier and IOP were abolished by indomethacin pretreatment, ${ }^{11,16}$ it seems that prostaglandins and other arachidonic acid metabolites are the mediators of the responses studied.

Two distinct endothelin receptor subtypes have been cloned and expressed. They are named $\mathrm{ET}_{\mathrm{A}}$ and $\mathrm{ET}_{\mathrm{B}}$. The $\mathrm{ET}_{\mathrm{A}}$ receptor selectively interacts with ET-1, whereas the $\mathrm{ET}_{\mathrm{B}}$ receptor is not selective. ${ }^{18}$ Activation of $\mathrm{ET}_{\mathrm{A}}$ and $\mathrm{ET}_{\mathrm{B}}$ receptors has been shown to stimulate phospholipase $C$, increase turnover of phosphoinositides, and increase intracellular calcium concentration. These actions are thought to lead to ET-induced contraction in smooth muscles. ${ }^{14}$ Activation of calcium mobilisation by the $\mathrm{ET}_{\mathrm{A}}$ receptor and subsequent contraction of the muscles should increase aqueous outflow by traction on the scleral spur and thus lower IOP. It is predicted that an $\mathrm{ET}_{\mathrm{A}}$ receptor-selective agonist will be ocular hypotensive in humans and will mimic the outflow effect of ET-1 in the anaesthetised monkey eye. ${ }^{16}$ Whether activation of the $\mathrm{ET}_{\mathrm{B}}$ receptor affects IOP in humans is not established. However, Hague et al. ${ }^{19}$ reported that the $\mathrm{ET}_{\mathrm{B}}$ receptorselective agonist, sarafotoxin S6c, lowered IOP in rabbits, but with a clearly slower time of onset compared with ET-1. They suggested that the $\mathrm{ET}_{\mathrm{A}}$ receptor probably mediates the early phase, and that the $\mathrm{ET}_{\mathrm{B}}$ receptor plays a key role in the later phase of the ET effect. ET-1 increased production of $\mathrm{PGE}_{2}$ and cAMP in a dosedependent manner. ET-1 activation of CAMP formation apparently was mediated by the $\mathrm{ET}_{\mathrm{B}}$ receptor subtype. ${ }^{20}$ All these ET actions could affect the contractility of the ciliary muscle and are potentially important in regulating IOP. $^{21}$

In our model LT resulted in an extremely large and immediate elevation of aqueous humour ET-1 concentration. No similar response was observed in the untreated eyes. These results suggest that the elevation of aqueous ET-1 concentration was due to an increase in ET-1 release from the uveal tissue (iris pillars), probably caused by tissue damage. In the LT group IOP alteration was statistically significant at each of the follow-up times between eyes that underwent LT and untreated eyes. Compared with the pre-treatment value, IOP increased following LT. On the contrary, this increase was not seen in the untreated contralateral eyes of the same animals. 
In our experiment the IOP increase following LT seemed to represent the impact of the increased ET-1 level on aqueous humour dynamics, since exogenous ET-1 administered intracamerally and intravitreally in the rabbit has been found to have a similar effect on IOP, lasting at least for 5 days. ${ }^{22,23}$ In our model the IOP at $12 \mathrm{~h}$ after LT was significantly higher than the corresponding value for the untreated eyes of the same animals.

It was found in the previous experimental studies that the ET-1 induced IOP change is biphasic. ${ }^{3,22-24}$ In the rabbit exogenous ET-1 administration was followed by an immediate IOP rise within the first hours. This IOP elevation disappeared in at most $4 \mathrm{~h}$ after ET-1 administration, and subsequently a prolonged IOP reduction was found. ${ }^{22,25}$ In our model IOP was significantly lower in the LT group after the first day. It is well known that LT frequently causes both an initial increase and a subsequent decrease in IOP in the early post-laser hours and days. ${ }^{26,27}$ Since human LT is followed by an acute increase of the protein concentration in the aqueous humour, it is probable that the concentration of ETs, including ET-1, also becomes elevated in the anterior chamber after laser treatment. A clinically significant, immediate ET release following LT might explain the early, biphasic IOP change that consists of an acute IOP elevation mostly within the first $12 \mathrm{~h}$, and a later decrease. This biphasic IOP change is very similar to the IOP alterations caused by exogenous ET-1 administration in rabbits, though the IOP spike seems to occur earlier in the experiments than in clinical practice after LT. ${ }^{26,28}$ ET-1-induced biphasic IOP changes were hypothesised to be caused by the release of cyclooxygenase products. ${ }^{11}$ However, experimental indomethacin pre-treatment failed to block the IOP change induced by an $\mathrm{ET}_{\mathrm{B}}$ receptor agonist, sarafotoxin $\mathrm{S} 6 \mathrm{c}$, in the rabbit, ${ }^{23}$ and an $\mathrm{ET}_{\mathrm{A}}$ receptor-specific antagonist, BQ-123, inhibited both the early IOP rise and its later reduction, as well as the increase in $\mathrm{PGE}_{2}$ concentration in the aqueous humour following ET-1 administration. ${ }^{25}$ These data from the literature suggest that IOP changes induced by ET- 1 are, at least in part, mediated directly via ET receptors without any role of prostaglandins. ${ }^{23,25}$ On the basis of these results, it is not surprising that, similar to corticosteroid pretreatment, ${ }^{26,27}$ topical non-steroid anti-inflammatory medication failed to reduce early IOP spikes following LT, though both types of medication did reduce inflammation. ${ }^{29}$

In summary, our findings suggest that the significant elevation of aqueous humour ET-1 concentration after LT and the corresponding relative IOP increase during the first hours after laser treatment may provide a possible explanation for the mechanism of the early IOP changes frequently seen following LT in clinical practice.

However, further studies are necessary to elucidate the connection between aqueous humour ET-1 concentration and IOP in the human eye, which is considerably different from that of the rabbit in anterior chamber angle anatomy, as well as in physiological response to inflammation.

\section{References}

1. Chakravarthy U, Douglas AJ, Bailie JR, McKibben B, Archer DB. Immunoreactive endothelin distribution in ocular tissues. Invest Ophthalmol Vis Sci 1994;35:2448-54.

2. Lepple-Weinhues A, Becker M, Stahl F. Endothelin-like immunoreactivity in the aqueous humour and in conditioned medium from cultured ciliary epithelial cells. Curr Eye Res 1992;11:1041-6.

3. Erickson-Lamy K, Korbmacher C, Schuman J, Nathanson J. Effect of endothelin on outflow facility and accommodation in the monkey eye in vivo. Invest Ophthalmol Vis Sci 1991;32:492-5.

4. Weinreb RN, Weaver D, Mitchell MD. Prostanoids in rabbit aqueous humor: effect of laser photocoagulation of the iris. Invest Ophthalmol Vis Sci 1985;26:1087-92.

5. Unger WG, Perkins ES, Bass MS. The response of the rabbit eye to laser irradiation of the iris. Exp Eye Res 1974;19:367-77.

6. Unger WG, Cole DF, Bass MS. Prostaglandin and neurogenically mediated ocular response to laser irradiation of the rabbit iris. Exp Eye Res 1977;25:209-20.

7. Unger WG, Butler JM, Cole DF. Prostaglandin and an increased sensitivity of the sympathetically denervated rabbit eye to laser-induced irritation of the iris. Exp Eye Res 1981;32:699-707.

8. L'Esperance FA. Clinical photocoagulation with the frequency-doubled neodymium-YAG laser. Am J Ophthalmol 1971;71:631-8.

9. MacCumber MW, Jampel HD, Snyder SH. Ocular effects of the endothelin: abundant peptides in the eye. Arch Ophthalmol 1991;109:705-9.

10. Okada K, Sugiyama K, Haque SR, Taniguchi T, Kitazawa Y. Biphasic intraocular pressure response to intravitreal injection of endothelin-1. J Jpn Ophthalmol Soc 1994;98:935-41.

11. Granstam E, Wang L, Bill A. Effects of endothelins (ET-1, ET2 and ET-3) in the rabbit eye: role of prostaglandins. Eur J Pharmacol 1991;194:217-23.

12. Lepple-Wienhues A, Stahl F, Willner U, Schaefer R, Wiederholt M. Endothelin-evoked contractions in bovine ciliary muscle and trabecular meshwork: interaction with calcium, nifedipine and nickel. Curr Eye Res 1991;10:983-9.

13. Abdel-Latif AA, Zhang Y. Species differences in the effects of endothelin-1 on myoinositol triphosphate accumulation, cyclic AMP formation and contraction of isolated iris sphincter of rabbit and other species. Invest Ophthalmol Vis Sci 1991;32:2432-8.

14. Rubanyi GM, Polokoff MA. Endothelins: molecular biology, biochemistry, pharmacology, physiology, and pathology. Pharmacol Rev 1994;46:325-415.

15. Abdel-Latif AA, Zhang Y, Yousufzai SYK. Endothelin-1 stimulates the release of arachidonic acid and prostaglandins in rabbit iris sphincter smooth muscle: activation of phospholipase $A_{2}$. Curr Eye Res 1991;10:259-65.

16. Matsumoto S, Yorio T, Magnino PE, DeSantis L, Pang IH. Endothelin-induced changes of second messengers in cultured human ciliary muscle cells. Invest Ophthalmol Vis Sci 1996;37:1058-66.

17. Naveh N, Rosner M, Gutman LZ, Rosen N. Comparison of the effects of argon and neodymium:YAG laser iridotomy on prostaglandin $\mathrm{E}_{2}$ and blood-aqueous barrier disruption. Ophthalmic Res 1990;22:253-8.

18. Arai H, Hori S, Aramori I, Ohkubo H, Nakanishi H. Cloning and expression of a cDNA encoding an endothelin receptor. Nature 1990;348:730-2. 
19. Hague MSR, Taniguchi T, Sugiyama K, Okada K, Kitazawa $\mathrm{Y}$. The ocular hypotensive effect of the $\mathrm{ET}_{\mathrm{B}}$ receptor selective agonist, sarafotoxin S6c, in rabbits. Invest Ophthalmol Vis Sci 1995;36:804-8.

20. El-Mowafy A, Abdel-Latif A. Characterization of iris sphincter smooth muscle endothelin receptor subtypes which are coupled to cyclic AMP formation and polyphosphoinositide hydrolysis. J Pharmacol Exp Ther 1994;268:1341-51.

21. Shoji N, Oshika T, Masuda K. Inflammatory reaction via arachidonic acid cascade after intravitreal injection of endothelin-1. Curr Eye Res 1998;17:205-10.

22. Taniguchi T, Okada K, Haque MS, Sugiyama K, Kitazawa Y. Effects of endothelin-1 on intraocular pressure and aqueous humour dynamics in the rabbit eye. Curr Eye Res 1991;13:461-4.

23. Hague MSR, Sugiyama K, Tanaguchi T, Okada K, Nakai $Y$, Kitazawa Y. The effects of ETB receptor-selective agonist on IOP and blood-aqueous barrier in rabbit eyes: role of cyclooxygenase products. Jpn J Ophthalmol 1995;39:360-7.
24. Sugiyama T, Moriya S, Oku H, Azuma I. Association of endothelin-1 with normal tension glaucoma; clinical and fundamental studies. Surv Ophthalmol 1995;39(Suppl 1):S49-56.

25. Hague MSR, Sugiyama K, Taniguchi T, Kitazawa Y. Effects of $\mathrm{BQ}-123$, an $\mathrm{ET}_{\mathrm{A}}$ receptor-selective antagonist, on changes of intraocular pressure, blood-aqueous barrier and aqueous prostaglandin concentrations caused by endothelin- 1 in rabbit. Jpn J Ophthalmol 1996;40:26-32.

26. Ruderman JM, Zweig KO, Wilensky JT, Weinreb RN. Effects of corticosteroid pretreatment on argon laser trabeculoplasty. Am J Ophthalmol 1983;96:84-9.

27. Shin DH, Frenkel REP, David R, Cheetham JK, and the Fluorometholone-Laser Trabeculoplasty Study Group. Effect of topical anti-inflammatory treatment on the outcome of laser trabeculoplasty. Am J Ophthalmol 1996;122:349-54.

28. Pappas HR, Berry DP, Partamian L, Hertzmark E, Epstein DL. Topical indomethacin therapy before argon laser trabeculoplasty. Am J Ophthalmol 1985;99:571-5.

29. Weinreb RN, Robin AL, Baerveldt G, Drake MV, Blumenthal $\mathrm{M}$, Wilensky J. Flurbiprofen pretreatment in argon laser trabeculoplasty for primary open-angle glaucoma. Arch Ophthalmol 1984;102:1629-32. 